\title{
Air-water two-phase flow through U-bend, sudden expansion and sudden contraction in rectangular mini-channels
}

\author{
M. Sadatomi ${ }^{1}$, S. Miyagawa ${ }^{1}$, B. Santoso ${ }^{2}$ \& A. Kawahara ${ }^{1}$ \\ ${ }^{1}$ Graduate School of Science and Technology, Kumamoto University, \\ Kumamoto, Japan \\ ${ }^{2}$ Department of Mechanical Engineering, Engineering Faculty, \\ Sebelas Maret University, Indonesia
}

\begin{abstract}
The evaluation of pressure loss in gas-liquid two-phase flow through singularities is important for designing compact heat exchangers such as cooling devices in electronic equipment. However, the accurate evaluation methods are scarce especially for mini-channel flow. In the present study, air-water twophase flow and water single-phase flow experiments were conducted at room temperature using three kinds of horizontal rectangular mini-channels each with a U-bend, sudden expansion, and sudden contraction. The width and depth of the rectangular cross-section of the channel with U-bend were $3 \mathrm{~mm}$ by $3 \mathrm{~mm}$, while those with sudden expansion and/or sudden contraction were $3 \mathrm{~mm}$ by $3 \mathrm{~mm}$ and $6 \mathrm{~mm}$ by $3 \mathrm{~mm}$. The flow regimes covered were bubble, slug and annular flows. Reynolds number range for water was from 240 to 9300 , while that for air from 17 to 3200 . The local pressures upstream and downstream from the singularity were measured with calibrated pressure sensors to determine the frictional pressure drop in the channels upstream and downstream from the singularity, together with the pressure drop at the singularity. Video photography of flows was also conducted to determine flow regime, bubble velocity and void fraction. In the analysis, the frictional pressure drop data and the pressure drop data at the singularity were compared with calculations by various correlations in literatures. Results of such experiment and analysis are described in the present paper.

Keywords: two-phase flow, pressure drop, void fraction, U-bend, sudden expansion, sudden contraction, rectangular mini-channel.
\end{abstract}




\section{Introduction}

A lot of studies have been conducted for two-phase gas-liquid flows in ordinary sized channels with singularities as reported by, say, Chisholm [1]. Recently, however, compact heat exchangers with phase change, such as cooling devices of electronic equipment, are miniaturized. For designing such devices, it is very important to estimate the characteristics of heat transfer and pressure drop of two-phase flow in mini- and micro- channels of $100 \mu \mathrm{m}$ to $10 \mathrm{~mm}$ not only for straight cannel flows but also for flows with singularities.

Recently, Kawahara et al. [2-4] in our group started to study two-phase flow in square and rectangular micro-channel with singularities arranged on a horizontal plane. The cross-sectional sizes of the channels are $300 \mu \mathrm{m}$ by $300 \mu \mathrm{m}$ for the channel with U-bend [2, 3], and $300 \mu \mathrm{m}$ by $300 \mu \mathrm{m}$ and $300 \mu \mathrm{m}$ by $600 \mu \mathrm{m}$ for the channel with sudden expansion and/or sudden contraction [4]. They changed the working liquids to study the effects of liquid properties, i.e., surface tension, viscosity and density.

In the present study, experiments have been conducted with a new test channel whose cross-section is ten times larger than Kawahara et al.'s, and with air and water as the working fluids to know the effects of channel size. Main parameters measured are frictional pressure drop, bubble velocity and void fraction in the straight channel sections, and pressure drops at U-bend, sudden expansion and sudden contraction. In the analysis, pressure drop data at the singularities are compared with the calculations by correlations in literatures for U-bend [5-11], sudden contraction [12-16] and sudden expansion [13, 17-20]. Results of the experiments and the analysis are described in the present paper.

\section{Experiment}

\subsection{Experimental apparatus}

Figure1 shows the present test channels with (a) U-bend and (b) sudden expansion and/or contraction placed on a horizontal plane. The cross-section of the channel with U-bend is rectangular of $2.99 \mathrm{~mm}$ in depth and $3.11 \mathrm{~mm}$ in width, and the hydraulic equivalent diameter, $D_{H}$, is $3.05 \mathrm{~mm}$. Since curvature radius, $R$, is $6.0 \mathrm{~mm}$, thus the radius ratio, $2 R / D_{H}$, is about 4.0 . The cross-section of the channel with sudden expansion and/or contraction is also rectangular. The depth, the width and the hydraulic diameter for the narrow channel are $3.01 \mathrm{~mm}, 2.88 \mathrm{~mm}$ and $2.95 \mathrm{~mm}$, while those for the wide channel are $3.03 \mathrm{~mm}$, $6.0 \mathrm{~mm}$ and $4.03 \mathrm{~mm}$, thus the ratio of expansion and/or contraction is about 2 and/or $1 / 2$.

Experiments were conducted for water single-phase flow and air-water twophase flow at room temperature. The ports 1 and 3 in Fig. 1 (a) are water and air inlets, while the port 2 is usually closed and the port 4 is exit of air-water mixture. Volume flow rate of air, $Q_{G}$, was measured with a couple of flow meter with different range within $2 \%$, while that of water, $Q_{L}$, with a flow meter within 1\%. P1 to P9 are the pressure taps, and pressure at P3 was measured with a 
gauge type pressure transducer. The pressures at other pressure taps were determined from the pressure difference between each tap and the P3 tap measured with a couple of differential pressure transducer. The accuracy of the pressure measurement was within $3.5 \mathrm{~Pa}$ from a calibration test. In order to obtain accurate time averaged pressures, the output signals from the sensors were fed to a personal computer via $\mathrm{A} / \mathrm{D}$ converter at $1 \mathrm{kHz}$ and total data point of 2000. However, for highly fluctuating flows, the data point was increased up to 6000.

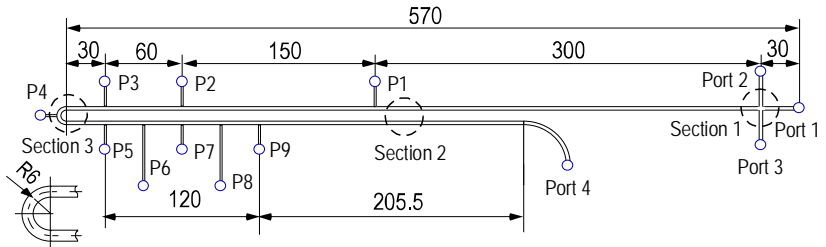

(a) Test channel with U-bend

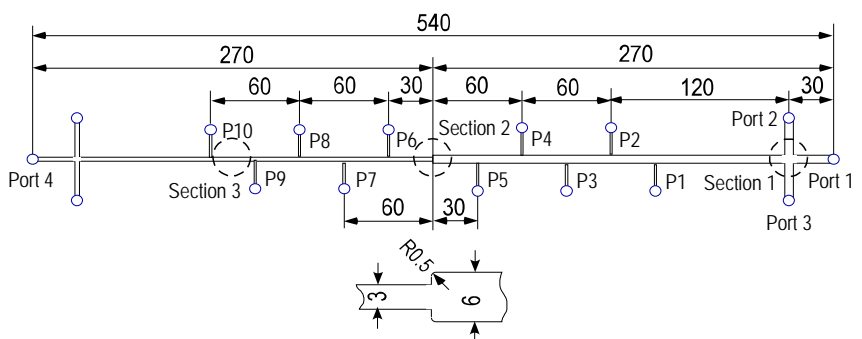

(b) Test channel with sudden expansion and/or contraction

Figure 1: Test channels.

In two-phase flow experiments, in addition to the pressure measurements, a high-speed video photography at 1000-4000 frames/s was conducted to determine flow pattern and bubble velocity, $u_{G}$, in bubbly and slug flows in three sections marked with broken circles in Fig. 1. Furthermore, void fraction, $\alpha$, was determined by substituting the $u_{G}$ and the gas volumetric flux, $j_{G}$, into $\alpha=j_{G} u_{G}$.

The ranges of volumetric fluxes of water and air for the U-bend channel are $0.1<j_{L}<2.0 \mathrm{~m} / \mathrm{s}$ and $0.08<j_{G}<10.1 \mathrm{~m} / \mathrm{s}$, and those of non-dimensional parameters defined by eqn. (1) are $240<R e_{L}<5000,20<R e_{G}<3100,0.4<$ $W e_{L}<165,0.0004<W e_{G}<7.2,1.22<B o<1.23$ and $0.002<C a<0.003$.

$$
\operatorname{Re}_{k}=\frac{\rho_{k} j_{k} D_{H}}{\mu_{k}}, W e_{k}=\frac{\rho_{k} j_{k}^{2} D_{H}}{\sigma}, B o=\frac{\left(\rho_{L}-\rho_{G}\right) g D_{H}{ }^{2}}{\sigma}, C a=\frac{\mu_{L} j_{L}}{\sigma},
$$

Here, the subscript $k$ is $L$ for water and $G$ for air. The ranges of them for the narrow channel of the sudden expansion and the contraction channels are similar to those for the U-bend channel. The flow regimes covered were bubbly, slug and annular flows, but mainly on bubbly and slug flows. 


\subsection{Reduction in pressure drop data}

Figures 2(a) and (b) show typical pressure distribution data for single-phase flow at $u_{n}=1.0 \mathrm{~m} / \mathrm{s}$. Here, $u_{n}$ is the mean velocity in the narrow channel of the contraction and the expansion channels and in the U-bend channel. The ordinate is the gauge pressure, while the abscissa the distance from the singularity. The pressure in the straight channel region drops lineally with the distance, while the pressure at the singularity suddenly drops or rises. Thus, the friction factor, $\lambda$, was determined from the distribution data in the straight channel regions.

$$
\lambda=\Delta P\left(2 D_{H} / \rho u^{2} L\right)
$$

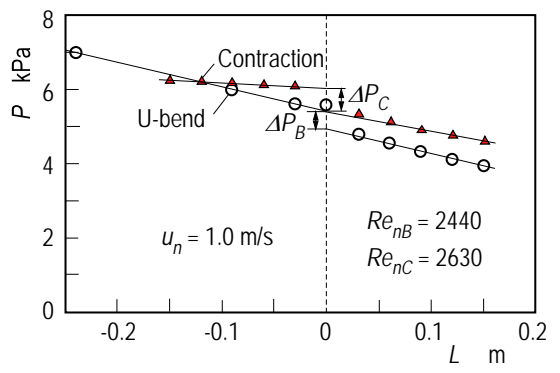

(a) U-bend and contraction channels

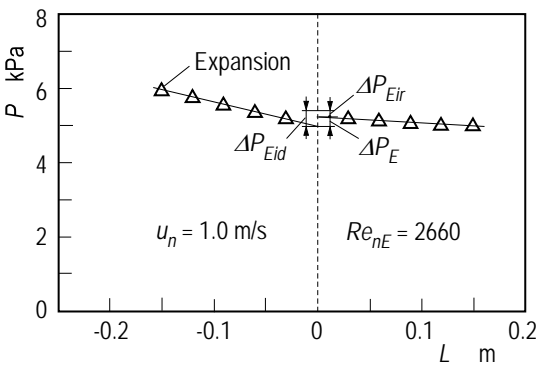

(b) Expansion channel

Figure 2: $\quad$ Typical pressure distribution measured at $u_{n}=1.0 \mathrm{~m} / \mathrm{s}$.

The pressure drop at the U-bend, $\Delta P_{B}$, the contraction, $\Delta P_{C}$, and the expansion, $\Delta P_{E}$, were determined by the pressure difference at $L=0$ extrapolated from the linear pressure distributions upstream and downstream from the singularity, as shown in Figs. 2(a) and (b). The pressure downstream from the expansion rises ideally by $\Delta P_{\text {Eid }}=\rho\left(u_{n}{ }^{2}-u_{w}{ }^{2}\right) / 2$, but the actual rise becomes $\Delta P_{E}$, smaller than $\Delta P_{E i d}$ by the irreversible pressure drop, $\Delta P_{E i r}$, for generating vortices at the inlet of the wide channel, etc. Such an irreversible pressure drop is not dealt with in the present study, but the pressure change as a whole, $\Delta P_{B}$, $\triangle P_{C}$, and $\Delta P_{E}$, is done by introducing the following pressure loss coefficients:

$$
k_{B}=\frac{\Delta P_{B}}{\rho u_{n}^{2} / 2}, \quad k_{C}=\frac{\Delta P_{C}}{\rho u_{n}^{2} / 2}, \quad k_{E}=\frac{\Delta P_{E}}{\rho u_{n}^{2} / 2}
$$

In two-phase flow, the pressure drop in the straight channel sections is composed of the friction and the acceleration components. Of these, the acceleration component can be evaluated from the difference in momentum fluxes of gas and liquid between the outlet and the inlet of the singularity:

$$
\Delta P_{a c c}=\left[\frac{G^{2} x^{2}}{\rho_{G} \alpha}+\frac{G^{2}(1-x)^{2}}{\rho_{L}(1-\alpha)}\right]_{\text {out }}-\left[\frac{G^{2} x^{2}}{\rho_{G} \alpha}+\frac{G^{2}(1-x)^{2}}{\rho_{L}(1-\alpha)}\right]_{\text {in }} .
$$


Here, $G$ is the total of gas and liquid mass fluxes, $x$ the quality, and $\alpha$ the void fraction. In the present study, the void fraction was calculated by substituting gas and liquid volume flow rates data, $Q_{G}$ and $Q_{L}$, into the Armand's correlation [25], which is applicable to the present void fraction data as described in Sec. 3.4:

$$
\alpha=0.833 \beta, \quad \beta=Q_{G} /\left(Q_{G}+Q_{L}\right)
$$

Though the acceleration component is only $0.005 \%$ at maximum of the total in the present experimental range, the frictional component was determined from the measured pressure drop by subtracting the calculated acceleration component.

\section{Experimental results and discussion}

\subsection{Frictional pressure drop in single-phase flow}

Figures 3(a), (b) show the friction data for the straight channels of the U-bend channel and the contraction channel against the Reynolds number. The data in turbulent flow are compared with the calculation by Blasius' equation, while those in laminar flow the calculation by the following equation [21].

$$
\lambda \operatorname{Re} / 4=24\left(1-1.3553 \alpha^{*}+1.9467 \alpha^{*^{2}}-1.7012 \alpha^{*^{3}}+0.9564 \alpha^{*^{4}}-0.2537 \alpha^{*^{5}}\right)
$$

Here, $R e=\rho u D_{H} / \mu$ and $\alpha^{*}$ is the aspect ratio of the rectangular channel.

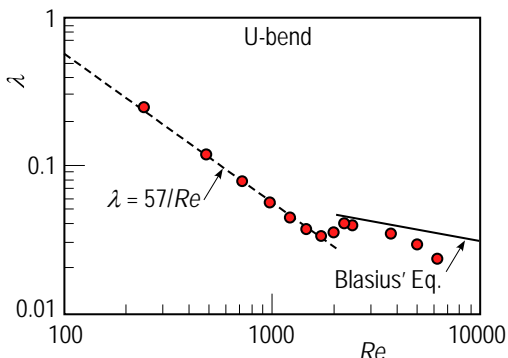

(a) U-bend channel

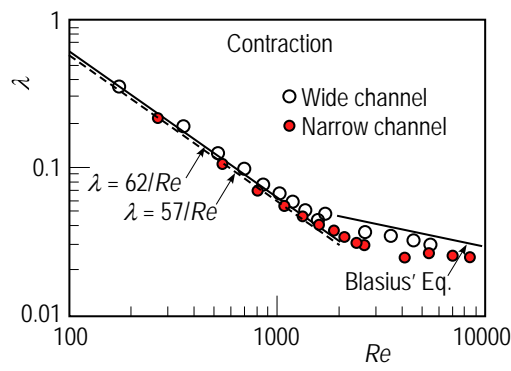

(b) Contraction channel

Figure 3: Friction factor data for the straight channels in single-phase flow.

In laminar flow region, the data agree well with the calculated curve, meaning the accurate measurements for the present experiments. In turbulent flow region, the data take lower value than the calculation and their trend is complex. In the U-bend channel, non-symmetrical flow caused by centrifugal force continues for a long distance, and the distance seems to increase with the Reynolds number. In the contraction channel, friction factor for the narrow channel decreases with increasing of Re similarly to laminar flow and approaches to the calculation by Blasius' equation. 


\subsection{Pressure drop at singularity in single-phase flow}

Figures 4(a)-(c) show the pressure loss coefficient data at the U-bend, the sudden contraction and the sudden expansion.

For the U-bend channel, the $k_{B}$ in turbulent flow take a minimum value of 0.7 at $R e_{n} \approx 3500$, and is not constant. For a comparison, calculated values by Ito's eqn. (7) in $\operatorname{Re}(r / R)^{2}>91$ [22, 23] and Idelshik's eqn. (8) [24] for turbulent flow in ordinary sized U-bend with circular cross-section of radius $r$ and curvature radius $R$ is drawn as broken curve and solid curve in Fig. 4(a).

$$
k_{B}=0.00241 \alpha \theta \operatorname{Re}^{-0.17}(R / r)^{0.84}-\lambda\left(\pi R / D_{H}\right), \alpha=1+116(R / r)^{-4.52} .
$$

Here, $\theta$ is 180 degree for U-bend, the friction factor, $\lambda$, is given by Ito's previous paper [23].

$$
k_{B}=\lambda\left(\pi R / D_{H}\right)+0.294 \sqrt{\left(R / D_{H}\right)}, \lambda=0.3164 \operatorname{Re}_{L}^{-0.25} .
$$

The resulting $k_{B}$ by eqn. (7) is less than $1 / 3$ of the present data, and that by eqn. (8) is less than $2 / 3$ of the present data. The disagreement between the data and the calculations is presumably attributable to the difference in the crosssectional shape and the channel size.

For the contraction channel, $k_{C}$ in turbulent flow is well correlated with:

$$
k_{C}=4.59 \mathrm{Re}_{n}^{-0.16} .
$$

Here, $R e_{n}$ is the Reynolds number for the narrow channel downstream from the sudden contraction. In common text books of "Fluid Mechanics", $k_{C}$ is given by

$$
k_{C}=\left(1 / C_{C}-1\right)^{2}
$$

The contraction coefficient, $C_{C}$, for ordinary sized circular pipes is taken as 0.59 at a maximum. However, $C_{C}$ for the present contraction channel is between 0.44 and 0.5 as shown in Fig. 4(b), and $C_{C}$ for Kawahara et al.'s microchannel with contraction [4] was 0.336 in $R e_{n}>80$. This suggests that $C_{C}$ decreases with the channel size in mini- and micro-channels.

For the expansion channel, $k_{E}$ in turbulent flow is about 0.4 , but with decreasing of Reynolds number it increases to a maximum value of about 0.84 and decreases. In common text books of "Fluid Mechanics", $k_{E}$ for ordinary sized circular pipes is given by the well-known Borda-Carnot's formula:

$$
k_{E} \approx\left(1-\sigma_{A}\right)^{2} .
$$

Here, $\sigma_{A}$ is the area ratio of the narrow channel to the wide channel, $A_{n} / A_{w}$, and 0.5 for the present expansion channel, thus $k_{E}$ by eqn. (12) is 0.25 . This suggests that $k_{E}$ increases with decreasing of the channel size in mini- and micro-channels. 


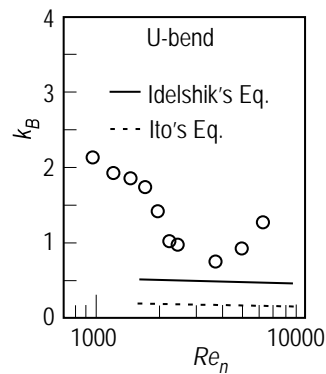

(a) U-bend channel

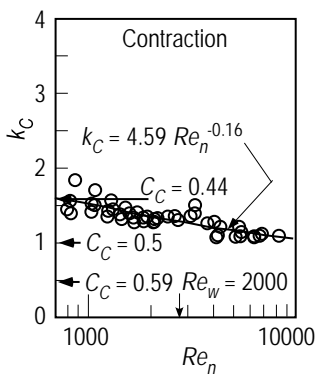

(b) Contraction channel

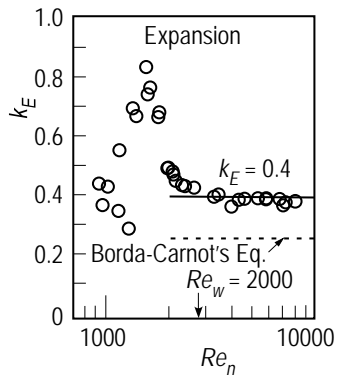

(c) Expansion channel

Figure 4: $\quad$ Pressure loss coefficient in single-phase flow.

\subsection{Flow pattern in two-phase flow}

Figures 5(a)-(c) show typical flows in the U-bend channel at $j_{L}=0.5 \mathrm{~m} / \mathrm{s}$, respectively for a bubbly flow at $j_{G}=0.08 \mathrm{~m} / \mathrm{s}$, a slug flow at $j_{G}=0.5 \mathrm{~m} / \mathrm{s}$ and an annular flow at $j_{G}=10 \mathrm{~m} / \mathrm{s}$. The picture of air-water mixing section is also shown in Fig. 5(a). Air bubbles in Fig. 5(a) flow inside and water flows outside of the bend due to the centrifugal force. The thickness of liquid film in Fig. 5(c) is thicker in the outside than the inside, and the difference in liquid film thickness continued to four times of the channel width downstream from the Ubend exit.

Figures 6(a)-(c) show typical flows in the contraction channel at $j_{L}=0.5 \mathrm{~m} / \mathrm{s}$, respectively for a bubbly flow, a slug flow and an annular flow. Small bubbles in the wide channel in Fig. 6(a) became slender after entering into the narrow channel and became large gas bubbles, being longer than the channel width. Thus, there exists a bubbly flow in the wide channel and a slug flow in the narrow channel at a transition to slug flow. In Fig. 6(c), the vena contracta seen in single-phase flow was confirmed in the gas core flow in the narrow channel downstream from the sudden contraction.

Figures 7(a)-(c) show typical flows in the expansion channel at $j_{L}=0.5 \mathrm{~m} / \mathrm{s}$, respectively for a bubbly flow, a slug flow and an annular flow. In Fig. 7(b), large gas bubbles in the narrow channel broke into small distorted bubbles in the wide channel, and the flow pattern in the wide channel became bubbly flow. In Fig. 7(c), twin vortices occurred in the dead water zone in the wide channel just downstream from the sudden expansion.

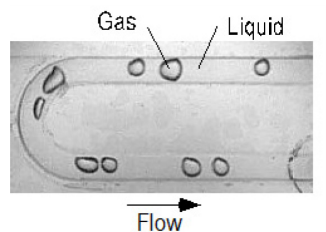

(a) $j_{G}=0.08 \mathrm{~m} / \mathrm{s}$
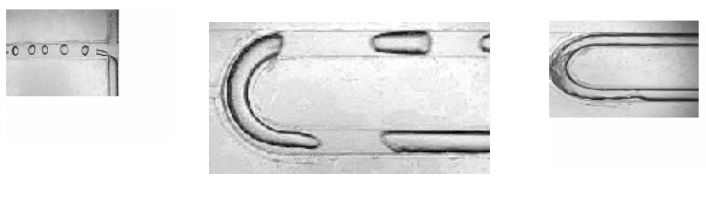

(b) $j_{G}=0.5 \mathrm{~m} / \mathrm{s}$

(c) $j_{G}=10 \mathrm{~m} / \mathrm{s}$

Figure 5: Typical flows in U-bend channel at $j_{L}=0.5 \mathrm{~m} / \mathrm{s}$. 


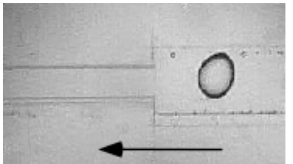

(a) $j_{G}=0.08 \mathrm{~m} / \mathrm{s}$

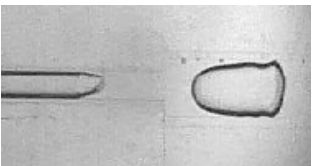

(b) $j_{G}=0.5 \mathrm{~m} / \mathrm{s}$

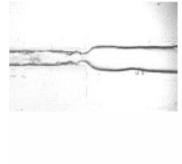

(c) $j_{G}=10 \mathrm{~m} / \mathrm{s}$

Figure 6: Typical flows in contraction channel at $j_{L}=0.5 \mathrm{~m} / \mathrm{s}$.

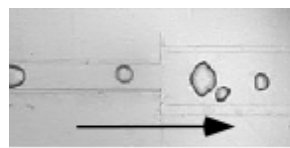

(a) $j_{G}=0.08 \mathrm{~m} / \mathrm{s}$

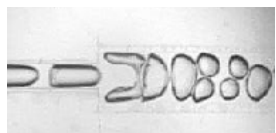

(b) $j_{G}=0.5 \mathrm{~m} / \mathrm{s}$

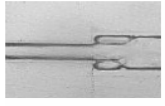

(c) $j_{G}=10 \mathrm{~m} / \mathrm{s}$

Figure 7: Typical flows in expansion channel at $j_{L}=0.5 \mathrm{~m} / \mathrm{s}$.

\subsection{Bubble velocity and void fraction in two-phase flow}

Figures 8(a)-(c) show the void fraction data at each observation section, $\alpha$, determined from the bubble velocity data against the gas-phase volume flow rate fraction, $\beta$. All $\alpha$ data agree well with $\alpha=0.833 \beta$, Armand's correlation [25] applicable to horizontal circular pipe flows, regardless of the observed positions.

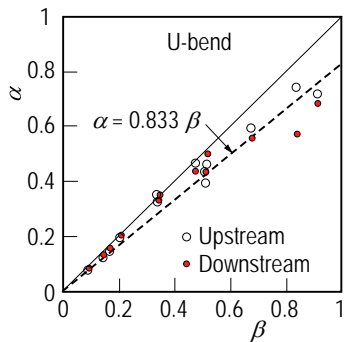

(a) U-bend channel

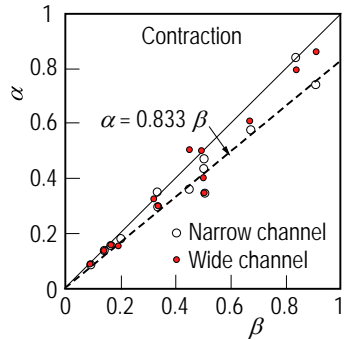

(b) Contraction channel

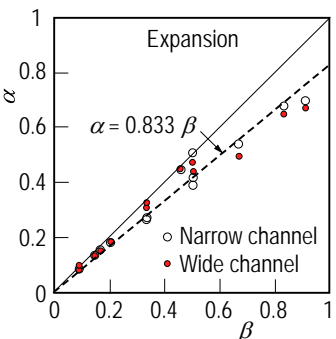

(c) Expansion channel

Figure 8: $\quad$ Void fraction in bubbly and slug flow.

\subsection{Pressure drop at singularity in two-phase flow}

Figure 9 shows two-phase pressure drop data at the sudden contraction, $\Delta P_{C}$, against the quality, $x$. The data of the first and the second measurements are plotted as open and colored symbols. At a fixed $j_{L}$ of $0.5,1.0$ and $2.0 \mathrm{~m} / \mathrm{s}, \Delta P_{C}$ increases with $x$, and the data in the first and the second measurements close each other. At a fixed $j_{L}$ of $0.1 \mathrm{~m} / \mathrm{s}$, however, the trend of the data is not monotonic, and the data in two measurements are not close. This means that the accuracy of the $\Delta P_{C}$ data is low at $j_{L}=0.1 \mathrm{~m} / \mathrm{s}$ and high at $j_{L}=0.5,1.0$ and 2.0 $\mathrm{m} / \mathrm{s}$. Although the figures are omitted, the accuracy of the data for the U-bend channel and the expansion channel is low at $j_{L}=0.1$ and $0.5 \mathrm{~m} / \mathrm{s}$. 


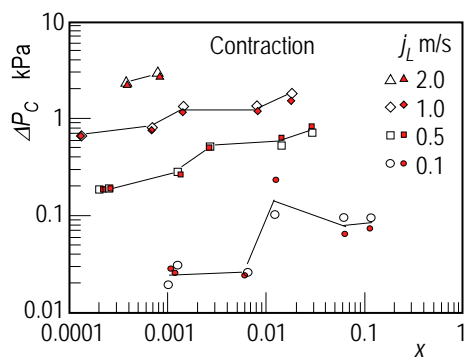

Figure 9: $\quad$ Two-phase pressure drop at sudden contraction.

Singularity pressure drop correlations in literatures are tested against the present data. For evaluating the accuracy in prediction, the following absolute mean and root mean square error are used. The reason is the accuracy of the $\Delta P$ data was low in low $\Delta P$ data and high in high $\Delta P$ data, and the evaluation by weighting the high $\Delta P$ data is reasonable.

$$
\varepsilon_{M}=\sum\left(\Delta P_{C a l}-\Delta P_{E x p}\right) / N, \varepsilon_{R M S}=\sqrt{\sum\left(\Delta P_{C a l}-\Delta P_{E x p}\right)^{2} /(N-1)} .
$$

Table 1 lists the $\varepsilon_{M}$ and the $\varepsilon_{R M S}$ of seven U-bend pressure drop correlations against the present data. Of these, Chisholm's correlation [9] with Idelshik's $k_{B}$ correlation in eqn. (8) is the best, which is recommended by Padilla et al. [26]. Table 2 lists those of five sudden contraction pressure drop correlations. Of these, the Schmidt and Friedel's correlation [14] is the best. Table 3 lists those of five sudden expansion pressure drop correlations. Of these, Wadle's correlation [18] is the best.

Figures 10(a)-(c) compare two-phase singularity pressure drop between experiment and calculation, respectively by Chisholm's correlation [9] for the Ubend, Schmidt and Friedel's correlation [14] for the sudden contraction and Wadle's correlation [18] for the sudden expansion, which showed the best predictions for the present data. Most of the data in $0.5<j_{L}<2.0 \mathrm{~m} / \mathrm{s}$ are well

Table 1: $\quad$ Mean and RMS errors of U-bend pressure drop correlations.

\begin{tabular}{|l|c|c|l|l|}
\hline Correlation & $\varepsilon_{M} \mathrm{kPa}$ & $\varepsilon_{R M S} \mathrm{kPa}$ & Reference & Remarks \\
\hline Chisholm's B type [5] & -0.447 & 0.967 & {$[5]$} & \\
\hline Chisholm's C type [6] & 0.433 & 1.438 & {$[6]$} & \\
\hline Geary [7] & -0.735 & 1.292 & {$[7]$} & \\
\hline Usui et al. [8] & -0.666 & 1.179 & {$[8]$} & \\
\hline Chisholm [1] & $\mathbf{0 . 2 0 1}$ & $\mathbf{1 . 0 3 9}$ & {$[9,26]$} & \\
\hline Chen et al. [10] & -0.44 & 0.921 & {$[10]$} & Mini-channel \\
\hline Domenski and Harmes [11] & 1.256 & 3.42 & {$[11]$} & Mini-channel \\
\hline
\end{tabular}


Table 2: Mean and RMS errors of sudden contraction pressure drop correlations.

\begin{tabular}{|l|c|c|l|l|}
\hline Correlation & $\varepsilon_{M} \mathrm{kPa}$ & $\varepsilon_{R M S} \mathrm{kPa}$ & Reference & Remarks \\
\hline Chisholm [9] & 4.424 & 7.56 & {$[12]$} & \\
\hline Collier and Thom [13] & 0.423 & 1.121 & {$[13]$} & \\
\hline Schmidt and Friedel [14] & $\mathbf{- 0 . 0 7 9}$ & $\mathbf{0 . 2 1 1}$ & {$[14]$} & \\
\hline Abdelall et al. [15] & 0.639 & 1.263 & {$[15]$} & Mini-channel \\
\hline Chen et al. [16] & 5.689 & 16.787 & {$[16]$} & Mini-channel \\
\hline
\end{tabular}

Table 3: Mean and RMS errors of sudden expansion pressure drop correlations.

\begin{tabular}{|l|c|c|l|l|}
\hline Correlation & $\varepsilon_{M} \mathrm{kPa}$ & $\varepsilon_{R M S} \mathrm{kPa}$ & Reference & Remarks \\
\hline Chisholm and Sutherland [17] & 0.573 & 1.2 & {$[17]$} & \\
\hline Wadle [18] & $\mathbf{0 . 0 3 2}$ & $\mathbf{0 . 1 6 1}$ & {$[18]$} & \\
\hline Collier and Thom [13] & 0.157 & 0.356 & {$[13]$} & \\
\hline Schmidt and Friedel [19] & 0.147 & 0.332 & {$[19]$} & \\
\hline Attou and Bolle [20] & -0.078 & 0.223 & {$[20]$} & \\
\hline
\end{tabular}

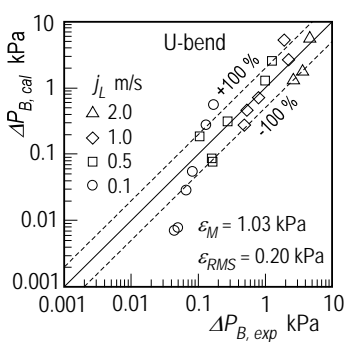

(a) Chisholm [9]

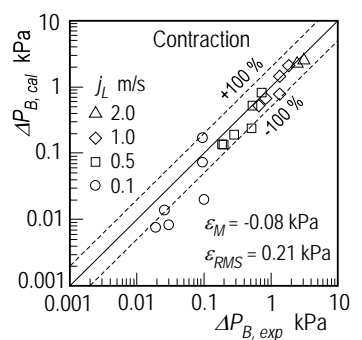

(b) Schmidt and Friedel [14]

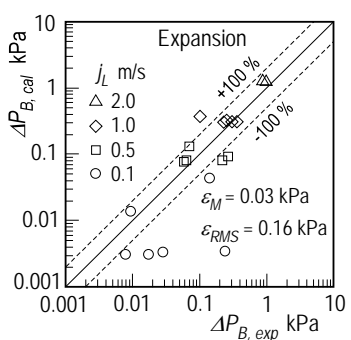

(c) Wadle [18]

Figure 10: Comparison of two-phase singularity pressure drop between experiment and calculation.

predicted within $100 \%$ in relative error. The data at $\mathrm{jL}=0.1 \mathrm{~m} / \mathrm{s}$, however, are not well predicted because of the inaccuracy in the measurements.

Further studies are needed to obtain better correlations of $\mathrm{kB}, \mathrm{kC}$ and $\mathrm{kE}$ respectively for $\mathrm{U}$-bend, sudden contraction and sudden expansion applicable to single-phase flows in various sized mini- and micro-channels. For that, it is necessary to conduct experiments using different working fluids and the present test channel together with new mini- and micro-channels with different size.

\section{Conclusions}

Air-water two-phase and water single-phase flow experiments were conducted at room temperature using horizontal rectangular mini-channels each with U-bend, sudden expansion and sudden contraction. The width and the depth of the rectangular cross-section of the channel with U-bend were $3 \mathrm{~mm}$ by $3 \mathrm{~mm}$, while 
those with the sudden expansion and/or the sudden contraction were $3 \mathrm{~mm}$ by 3 $\mathrm{mm}$ and $6 \mathrm{~mm}$ by $3 \mathrm{~mm}$. The flow regimes covered were bubble, slug and annular flows. The following are the main findings:

(1) The U-bend pressure loss coefficient in single-phase turbulent flow for the present channel was 1.5 times or more high than that for ordinary sized circular pipes. The sudden contraction one was also higher, and decreased with the channel size in mini- and micro-channels. The sudden expansion one was also higher, and increased with decreasing of the channel size.

(2) The present void fraction in bubbly and slug flows in the straight channel sections agreed well with the calculations by Armand's correlation [25].

(3) The present two-phase pressure drop at the U-bend was best predicted by Chisholm's correlation [9] with Idelshik's single-phase pressure loss coefficient [24]. That at the sudden contraction was best predicted by Schmidt and Friedel's correlation [14], and that at the sudden contraction by Wadle's correlation [18]. The data at $j_{L}=0.1 \mathrm{~m} / \mathrm{s}$, however, was not predicted well because of the inaccuracy in the measurements.

\section{Acknowledgements}

The authors appreciate the technicians in the machine shop at the Engineering Faculty of Kumamoto University for their cooperation in the manufacturing of the experimental apparatus and Mr. K. Tanaka for his experimental cooperation. Appreciation is also given to the Indonesian Government for financial support to Mr. B. Santoso who was a visiting researcher at Kumamoto University in those days.

\section{References}

[1] Chisholm, D., Two-Phase Flow in Pipelines and Heat Exchangers, George Godwin, London and New York, 1983.

[2] Kawahara, A., Sadatomi, M., Matsuo, H. and Shimokawa, S., Investigation of characteristics of gas-liquid two-phase flows in a rectangular microchannel with return bend, Proc. of ASME-JSME-KSME Joint Fluids Eng. Conf., Hamamatsu, Japan, 11 pages in CD-ROM, 2011.

[3] Kawahara, A., Sadatomi, M. and Shimokawa, S., Effects of return bend and liquid properties on pressure drop for two-phase flows in rectangular microchannels, Proc. of 2012 Japan-U.S. Seminar on Two-Phase Flow Dynamics, Tokyo, Japan, 7 pages in USB memory, 2012.

[4] Kusumaningsih, H., Kurihara, H., Kawahara, A. and Sadatomi, M., Effects of singularities on single-phase and gas-liquid two-phase flows in rectangular micro-channel, Proc. of ICMF2013, Jeju, Korea, 14 pages, 2013.

[5] Chisholm D, Pressure losses in bends and tees during steam-water flow, NEL Report No. 318, 1967.

[6] Chisholm, D., Predicting of pressure losses at changes of section, bends and throttling Devices, NEL Report No. 388, 1968. 
[7] Geary, D. F., Return bend pressure drop in refrigeration systems, ASHRAE Trans., 81, pp. 250-265, 1975.

[8] Usui K., Aoki S. and Inoue A., Flow behavior and pressure drop of twophase flow through C-shaped bend in vertical plane, (I) Upward flow, J. Nucl. Sci. Technol., 17, pp. 875-887, 1980.

[9] Chisholm, D., Two-Phase Flow in Pipelines and Heat Exchangers, George Godwin, London and New York, pp. 154-166, 1983.

[10] Chen, I. Y., Wang, C.-C. and Lin, S.Y., Measurements and correlations of frictional single-phase and two-phase pressure drops of R-410A flow in small U-type return bends, Exp. Therm. and Fluid Sci., 47, pp. 2241-2249, 2004.

[11] Domanski, P.A. and Herms, C.J.L., An improved correlation for two-phase pressure drop of R-22 and R-410A in $180^{\circ}$ return bend, Applied Thermal Eng., 28, pp. 793-800, 2008.

[12] Chisholm, D., Two-Phase Flow in Pipelines and Heat Exchangers, George Godwin, London and New York, pp. 184-192, 1983.

[13] Collier, J.G., and Thome, J.R., Convective Boiling and Condensation, 3rd ed., Oxford, New York, pp. 109-111, 1994.

[14] Schmidt, J. and Friedel, L., Two-phase flow pressure drop across sudden contractions in duct areas, Int. J. of Multiphase Flow, 23, pp. 283-299, 1997.

[15] Abdelall, E.F., Hahm, G., Ghiaasiaan, S.M., Abdel-Khalik, S.I., Jeter, S.S., Yoda, M., and Sadowski, D.L., Pressure drop caused by abrupt flow area changes in small channels, Exp. Therm. and Fluid Sci., 29, pp. 425-434, 2005.

[16] Chen, I.Y, Liu, C.C., Chien, K.H. and Wang, C.C., Two-phase flow characteristics across sudden expansion in small rectangular channel, Exp. Therm. and Fluid Sci., 32, pp. 696-706, 2007.

[17] Chisholm, D. and Sutherland, L.A., Prediction of pressure gradients in pipeline system during two-phase flow, Proc. Inst. of Mech. Engineers, 184, pt. 3C, pp. 24-32, 1969.

[18] Wadle, M., A new formula for the pressure recovery in an abrupt diffuser, Int. J. of Multiphase Flow, 15, pp. 241-256, 1989.

[19] Schmidt, J. and Friedel, L., Two-phase flow pressure change across sudden expansions in duct areas, Chem. Eng. Com., 141-142, pp. 175-190, 1995.

[20] Attou, A. and Bolle, L., A new correlation for the two-phase pressure recovery downstream from a sudden enlargement, Chem. Eng. Tech., 20, pp. 419-423, 1997.

[21] Shah, R.K. and London, A.L., Laminar Forced Convection in Ducts (Irvine, Jr. T.F. and Hartnett, J.P. ed., Advances in Heat Transfer Supplement I), Academic Press, New York, pp. 196-202, 1978.

[22] Ito, H., Pressure losses in smooth pipe bends, Trans. ASME, J. Basic Engineering, 82, pp.131-140, 1960.

[23] Ito, H., Friction factors for turbulent flow in curved pipes, Trans. ASME, J. Basic Eng., 81, pp.123-134, 1959. 
[24] Idelshik, I.E., Handbook of Hydraulic Resistance, 2nd ed., Hemisphere, New York, pp. 640, 1986.

[25] Armand, A. A., The resistance during the movement of a two-phase system in horizontal pipes, Izv. Vse. Teplotek. Inst., 1, pp.16-23 (AERE-Lib/Trans 828), 1946.

[26] Padilla, M., Revellin, M. and Bonjour, J., Prediction and simulation of twophase pressure drop in return bends, Int. J. of Refrigeration, 32, pp. 17761783, 2009. 